Bryn Mawr College

Scholarship, Research, and Creative Work at Bryn Mawr

College

Graduate School of Social Work and Social

Graduate School of Social Work and Social

Research Faculty Research and Scholarship

Research

2016

\title{
Syndemic factors associated with adult sexual HIV risk behaviors in a sample of Latino men who have sex with men in New York City
}

Omar Martinez

Sonya Arreola

Elwin $\mathrm{Wu}$

Miguel Muñoz-Laboy

Ethan Czuy Levine

See next page for additional authors

Let us know how access to this document benefits you.

Follow this and additional works at: http://repository.brynmawr.edu/gsswsr_pubs

Part of the Social Work Commons

\section{Custom Citation}

Martinez et al. 2016. Syndemic factors associated with adult sexual HIV risk behaviors in a sample of Latino men who have sex with men in New York City. Drug and Alcohol Dependence 166.1: 258-262.

This paper is posted at Scholarship, Research, and Creative Work at Bryn Mawr College. http://repository.brynmawr.edu/gsswsr_pubs/76

For more information, please contact repository@brynmawr.edu. 


\section{Authors}

Omar Martinez, Sonya Arreola, Elwin Wu, Miguel Muñoz-Laboy, Ethan Czuy Levine, Scott Edward Rutledge, Carolina Hausmann-Stabile, Larry Icard, Scott D. Rhodes, Alex Carballo-Diéguez, Carlos E. Rodríguez-Díaz, M. Isabel Fernandez, and Theo Sandfort 


\title{
Short communication
}

\section{Syndemic factors associated with adult sexual HIV risk behaviors in a sample of Latino men who have sex with men in New York City}

\author{
Omar Martinez ${ }^{\mathrm{a}, *}$, Sonya Arreola ${ }^{\mathrm{b}}$, Elwin $\mathrm{Wu}^{\mathrm{c}}$, Miguel Muñoz-Laboy ${ }^{\mathrm{d}}$, Ethan Czuy \\ Levine $^{\mathrm{e}}$, Scott Edward Rutledge ${ }^{\mathrm{f}}$, Carolina Hausmann-Stabile ${ }^{\mathrm{g}}$, Larry Icard ${ }^{\mathrm{h}}$, \\ Scott D. Rhodes ${ }^{\mathrm{i}}$, Alex Carballo-Diéguez ${ }^{\mathrm{j}}$, Carlos E. Rodríguez-Díaz ${ }^{\mathrm{k}}$, \\ M. Isabel Fernandez ${ }^{1}$, Theo Sandfort ${ }^{\mathrm{m}}$
}

\footnotetext{
a School of Social Work, College of Public Health, Temple University, 1301 Cecil B. Moore Avenue, Ritter Annex, 505, Philadelphia, PA 19122, United States b Global Forum on MSM and HIV, 436 14th Street, Suite 100, Oakland, CA 94612, United States

' School of Social Work at Columbia University, 1255 Amsterdam Avenue, New York, NY 10027, United States

d School of Social Work, College of Public Health, Temple University, 1301 Cecil B. Moore Avenue, Ritter Annex, 551, Philadelphia, PA 19122, United States

e Department College of Liberal Arts, Temple University, Philadelphia, PA 19122, United States

${ }^{\mathrm{f}}$ College of Public Health, Temple University, 1101 W. Montgomery Ave. 3rd Floor, Philadelphia, PA 19122, United States

' School of Social Work, College of Public Health, Temple University, 1301 Cecil B. Moore Avenue, Ritter Annex, Philadelphia, PA 19122, United States

h School of Social Work, College of Public Health, Temple University, Ritter Annex, Philadelphia, PA, United States

${ }^{\mathrm{i}}$ Wake Forest School of Medicine, Medical Center Boulevard, Winston-Salem, N.C. 27157, United States

${ }^{\mathrm{j}}$ HIV Center for Clinical and Behavioral Studies at the New York State Psychiatric Institute and Columbia University, 1051 Riverside Drive, Unit 15, New

York, NY 10032, United States

k University of Puerto Rico-Medical Sciences Campus, School of Public Health, PO Box 365067, San Juan, PR, 00936-5067, United States

${ }^{1}$ Behavioral Health Promotion Program, Nova Southeastern University, 2000 South Dixie Highway, Fort Lauderdale, FL, 33133, United States

$\mathrm{m}$ Clinical Sociomedical Sciences (in Psychiatry), Columbia University, 1051 Riverside Drive, Unit 15, NY, NY 10032, United States
}

\section{A R T I C L E I N F O}

\section{Article history:}

Received 26 April 2016

Received in revised form 8 June 2016

Accepted 27 June 2016

Available online $\mathrm{xxx}$

\section{Keywords:}

Syndemic conditions

Latino men who have sex with men

High-risk alcohol consumption

HIV risk behaviors

\begin{abstract}
A B S T R A C T
Objective: Syndemic theory has been proposed as a framework for understanding the role of multiple risk factors driving the HIV epidemic among sexual and gender minority individuals. As yet, the framework has been relatively absent in research on Latinos/as.

Methods: We used logistic regression to assess relationships among cumulative syndemic conditions including clinically significant depression, high-risk alcohol consumption, discrimination, and childhood sexual abuse - engagement with multiple partners and condomless anal intercourse (CAI) in a sample of 176 Latino men who have sex with men (MSM) in New York City.

Results: In bivariate analyses, an increase in the number of syndemic factors experienced was associated with an increased likelihood of reporting multiple partners and CAI. In multivariable analyses, participants with 2,3 , and 4 factors were significantly more likely to report multiple partners than those with 0 $(\mathrm{aOR}=4.66,95 \% \mathrm{CI}[1.29,16.85) ; \mathrm{aOR}=7.28,95 \% \mathrm{CI}[1.94,27.28]$ and $\mathrm{aOR}=8.25,95 \% \mathrm{CI}[1.74,39.24]$ respectively; $p<0.05$. Regarding CAI, only participants with 3 and 4 factors differed from those with 0 $\mathrm{aOR}=7.35,95 \% \mathrm{CI}[1.64,32.83]$ and $\mathrm{OR}=8.06,95 \% \mathrm{CI}[1.39,46.73]$ respectively.

Conclusions: Comprehensive approaches that address syndemic factors, and capitalize on resiliency, are needed to address the sexual health needs of Latino MSM.
\end{abstract}

¿c 2016 Elsevier Ireland Ltd. All rights reserved.

\footnotetext{
* Corresponding author.

E-mail addresses: omar.martinez@temple.edu (O. Martinez), sarreola@msmgf.org (S. Arreola),ew157@columbia.edu (E. Wu),miguel.munoz-laboy@temple.edu

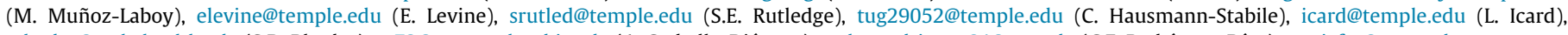
srhodes@wakehealth.edu (S.D. Rhodes), ac72@cumc.columbia.edu (A. Carballo-Diéguez), carlos.rodriguez64@upr.edu (C.E. Rodríguez-Díaz), mariafer@nova.edu (M.I. Fernandez), tgs2001@columbia.edu (T. Sandfort).
} 


\section{Introduction}

Latinos, and more specifically Latino men who have sex with men (MSM), are disproportionately impacted by HIV in the United States. Latinos represented 23\% of new infections in the U.S. in 2013 despite comprising only $16 \%$ of the population, and $81 \%$ these infections were specifically among MSM (Centers for Disease Control and Prevention, 2013). Recently, researchers at the Centers for Disease Control and Prevention (2016) reported that if current HIV diagnoses rates persist, 1 in 4 Latino MSM in the U.S. will be diagnosed with HIV during their lifetime.

Syndemic theory may be well suited to account for high rates of HIV/AIDS among Latino MSM (González-Guarda et al., 2011; Singer and Clair, 2003). This theory posits that multiple risk factors interact synergistically to increase vulnerability. Co-occurring conditions such as alcohol abuse, clinically significant depression, and violence may collectively influence HIV risk behaviors among Latino MSM (Mizuno et al., 2012; Wilson et al., 2014). Discrimination due to homophobia and racism has also been associated with HIV risk behaviors and binge-drinking among Latino MSM (Mizuno et al., 2012).

The present study extends recent work on syndemics and HIV risk among MSM (Latino and non-Latino; Halkitis et al., 2013; Mimiaga et al., 2015; Mizuno et al., 2012; O'Leary et al., 2014; Santos et al., 2014; Wilson et al., 2014) by including predominantly Spanish-speaking Latino MSM and incorporating multiple sexual risk behaviors. We hypothesized that a syndemic of psychosocial conditions would be associated with sexual risk.

\section{Methods}

\subsection{Participants}

We screened a community sample of 176 adult Latino MSM in English or Spanish to determine eligibility for an HIV prevention study. Enrollment began in January, 2014 and ended in March, 2014. We used a purposive stratified sampling strategy to diversify the sample in terms of country of origin, HIV status, HIV/STI testing history, and previous involvement in HIV research. Recruitment was guided by a community advisory board (CAB); recruitment venues included social media (e.g., Facebook; Martinez et al., 2014), community-based organizations, and word-of-mouth referrals (Martinez et al., 2015). Most of the participants were recruited through social media. Participants were recruited for a study on sexual health among Latino MSM, including strategies for HIV prevention interventions with same-sex couples.

\subsection{Ethics information}

The study was approved by the New York State Psychiatric Institute Institutional Review Board. We obtained a National Institutes of Health Certificate of Confidentiality to further protect participants from potential loss of confidentiality.

\subsection{Measures}

2.3.1. Demographic characteristics. We included the following demographic control variables: age (years), primary language (predominantly/exclusively Spanish, Spanish and English equally, predominantly/exclusively English), education (less than high school, high school diploma or GED, some college, associate's degree or higher), nation of origin (born in the U.S. vs. born outside of the U.S.), and relationship status (participants' self-reports of being in a same-sex relationship vs. not in a same-sex relationship).
Given the aims of the larger study, we only asked participants about same-sex relationships.

2.3.2. High-risk alcohol consumption. These measures were based on recommendations from the Substance Abuse and Mental Health Services Administration (SAMHSA, 2015). Participants were asked whether they ever had consumed 5 or more alcoholic beverages in a single occasion; those who answered "yes" were asked how often they had done so in the previous 30 days. As in prior research (O'Brien et al., 2008; SAMHSA, 2015), high-risk alcohol consumption was operationalized as: binge drinking ( 5 or more alcoholic drinks on the same occasion on at least 1 day in the past 30 days) or heavy drinking ( 5 or more alcoholic drinks on the same occasion on each of 5 or more days in the past 30 days). Participants who reported either binge or heavy drinking were classified as engaging in high-risk alcohol consumption.

2.3.3. Clinically significant depression. Depressive symptoms were measured using the short 10-item Center for Epidemiological Studies Depression (CES-D 10) scale (Chronbach's $\alpha=0.86$ ). This scale has been found valid and reliable for screening depressive symptoms in numerous populations (Cheng and Chan, 2008; Kohout et al., 1993; Wendy et al., 2012), including Latinos (Rhodes et al., 2010; Robison et al., 2002). We used the cut-off point of 10 (on a scale from 0 to 30 ), which equates to a cut-off point of 20 (on a scale from 0 to 60) for the full-length, 20-item CES-D (Andresen et al., 1994), and is thus more stringent than the commonly used cut-off point of 16 (Darnall et al., 2005; Pignone et al., 2002).

2.3.4. Discrimination. We used the Experiences of Discrimination (EOD) measure; it has been validated with Latino populations (Krieger et al., 2005). We asked participants whether they had ever experienced discrimination in any of the following areas: employment; housing; medical care; while getting services in a store or restaurant, or in a public setting; or from police or courts. Those who answered "yes" to any of these questions were coded as having experienced discrimination. For the purposes of this analysis, we did not distinguish among discrimination on the basis of ethnicity, sexuality, or other factors.

2.3.5. Childhood sexual abuse (CSA). Participants were asked whether they had experienced any sexual activity before the age of 17. Those who answered "yes" were then asked whether any such activity was "forced" or "coerced." All participants who answered "yes" to this follow-up question were classified as having experienced CSA.

2.3.6. Sexual risk behaviors. These measures were based on survey guidelines from the National Survey of Sexual Health and Behavior (Reece et al., 2010). We asked participants to report the number of male sexual partners in the past three months. Those who reported at least one partner were then asked to indicate the number of anal intercourse episodes in the past three months, as well as the number of times condoms were used. Participants were coded as having "multiple sexual partners" if they reported at least two partners, and as engaging in "condomless anal intercourse (CAI)" if they reported at least one incident of CAI.

2.3.7. Syndemic factors scale. Following Santos et al. (2014), we produced a syndemics scale ranging reflecting total reports of each of the following factors: high-risk alcohol consumption, clinically significant depression, childhood sexual abuse, and discrimination. Scores ranged from 0 (no factors reported) to 4 (all factors reported). 


\subsection{Data analysis}

We incorporated the syndemic factors scale as our main independent variable, and multiple sexual partners and condomless anal intercourse as dependent variables. We initially explored bivariate $\chi^{2}$ associations between each syndemic factor and each outcome, and between syndemics scale and each outcome. We then conducted factor analyses and reliability tests to determine whether our syndemic factors measured distinct risk factors, rather than providing multiple measures for substantially overlapping concepts. Finally, we constructed multivariable logistic regression models incorporating age, primary language, education, nation of origin, and relationship status as controls; reporting adjusted odds ratios (aOR) for both outcomes. A total of 172 participants provided data for all measures ( $98 \%$ of the original sample). Rather than impute missing values to accommodate such minor data loss, we retained only those participants for multivariable analysis.

Descriptive characteristics appear in Table 1. Bivariate and multivariable analyses appear in Table 2. Findings for control variables are not shown in Table 2, though we report on them here.

\section{Results}

\subsection{Sample characteristics}

The mean age of our sample $(n=176)$ was 33 years. Over half identified Spanish as their primary language ( $n=99,56 \%)$. Fourteen percent had not completed high school $(n=24)$, and $30 \%$ had earned a high school diploma or GED. Approximately one-third of participants were born in the U.S. $(n=50,29 \%)$. Two-thirds were in same-sex relationships $(n=118,67 \%)$. One-third $(n=60,34 \%)$ had previously tested positive for HIV. Slightly over half of participants reported multiple sexual partners $(n=92,53 \%)$ and $51 \%$ reported at least one incident of CAI in this period $(n=89)$.

Participants reported considerable rates across all syndemic factors. Nearly half reported binge or heavy drinking $(n=83,47 \%)$. Nearly two-thirds reported experiencing discrimination $(n=110$, $63 \%$ ), and $69 \%$ screened for depressive symptoms $(n=120)$. Approximately 1 in 5 reported childhood sexual abuse $(n=39,22 \%)$. Only $11 \%$ of participants reported no syndemic factors $(n=19)$, and $66 \%$ reported two or more factors $(n=115)$. In bivariate analyses with each syndemic factor (not shown in a table), reporting multiple partners was significantly associated with depression $\left(\chi^{2}[1]=4.18\right.$, $\mathrm{p}<0.05)$ and high risk drinking $\left(\chi^{2}[1]=12.33, \mathrm{p}<0.01\right)$, and marginally associated with childhood sexual abuse $\left(\chi^{2}[1]=2.81\right.$, $\mathrm{p}<0.10)$. Condomless anal intercourse was significantly associated with discrimination $\left(\chi^{2}[1]=3.94, \mathrm{p}<0.05\right)$ and high risk drinking $\left(\chi^{2}[1]=13.20, p<0.01\right)$, and marginally associated with depression $\left(\chi^{2}[1]=3.48, p<0.10\right)$. Factor analysis and chronbach's alpha reliability testing ( 1 retained factor, eigenvalue $=0.62$ ); $\alpha=0.46$ confirmed that the four variables in our syndemic scales were distinct (not shown in a table); in other words, our syndemics scale measured the cumulative impact of multiple unique risk factors.

\subsection{Multiple sexual partners}

Bivariate analysis found a significant relationship between number of syndemic factors and multiple sexual partners $\left(\chi^{2}[4]=13.74\right.$, $\mathrm{p}<0.05$ ). In multivariable analysis, participants who reported two, three, or four factors were significantly more likely to report multiple sexual partners than those who reported none $(\mathrm{aOR}=4.66,95 \%$ CI [1.29-16.85], $\mathrm{p}<0.05 ; \mathrm{aOR}=7.28,95 \% \mathrm{CI}$ [1.94-27.28], $\mathrm{p}<0.01$; $\mathrm{aOR}=8.25,95 \% \mathrm{CI}$ [1.74-39.24], $\mathrm{p}<0.05$; respectively). Moreover, the relative odds of having multiple partners increased as the number of factors increased. Relative to those who had not finished high
Table 1

Sample characteristics ( $\mathrm{n}=176$ unless otherwise specified).

\begin{tabular}{|c|c|}
\hline & $\mathrm{M}(\mathrm{SD})$ or $\mathrm{n}(\%)$ \\
\hline Age (M) & $33.37(9.10)$ \\
\hline $\begin{array}{l}\text { Primary Language } \\
\text { Predominantly or Exclusively Spanish } \\
\text { Spanish and English Equally } \\
\text { Predominantly or Exclusively English }\end{array}$ & $\begin{array}{l}99(56.25) \\
50(28.41) \\
27(15.34)\end{array}$ \\
\hline $\begin{array}{l}\text { Education }(\mathrm{n}=175) \\
\text { Less than High School } \\
\text { High School or GED } \\
\text { Some College } \\
\text { Associate's Degree or Higher }\end{array}$ & $\begin{array}{l}24(13.71) \\
53(30.29) \\
46(26.29) \\
52(29.71)\end{array}$ \\
\hline Born in the United States $(n=175)$ & $50(28.57)$ \\
\hline In a Same-Sex Relationship ( $\mathrm{n}=175)$ & $118(67.43)$ \\
\hline HIV Positive & $60(34.09)$ \\
\hline $\begin{array}{l}\text { Alcohol Consumption in Past } 30 \text { Days } \\
\text { Binge Drinking } \\
\text { Heavy Drinking } \\
\text { No High-Risk Drinking }\end{array}$ & $\begin{array}{l}36(20.45) \\
47(26.70) \\
93(52.84)\end{array}$ \\
\hline Clinically Significant Depression $(n=173)$ & $120(69.36)$ \\
\hline Experiences of Discrimination & $110(62.50)$ \\
\hline Child Sexual Abuse & $39(22.16)$ \\
\hline $\begin{array}{l}\text { Syndemics Scale } \\
0 \text { Factors } \\
1 \text { Factor } \\
2 \text { Factors } \\
3 \text { Factors } \\
4 \text { Factors }\end{array}$ & $\begin{array}{l}19(10.98) \\
39(22.54) \\
53(30.64) \\
44(25.43) \\
18(10.40)\end{array}$ \\
\hline $\begin{array}{l}\text { Sexual Behaviors in Past } 3 \text { Months } \\
\text { Frequency of Anal Sex Acts (M) } \\
\text { Multiple Sexual Partners } \\
\text { Condomless Anal Intercourse }\end{array}$ & $\begin{array}{l}26.50(34.39) \\
92(52.27) \\
89(50.57)\end{array}$ \\
\hline $\begin{array}{l}\text { Recruitment Venue }(\mathrm{n}=172) \\
\text { Community-based organization } \\
\text { Hispanic AIDS Forum } \\
\text { Betances } \\
\text { BOOM! Health } \\
\text { Latino Commission on AIDS } \\
\text { LGBT Center }\end{array}$ & $\begin{array}{r}17(10) \\
7(42) \\
3(17) \\
2(12) \\
3(17) \\
2(12)\end{array}$ \\
\hline $\begin{array}{l}\text { Social Media } \\
\text { Facebook } \\
\text { Grindr } \\
\text { Jack'd } \\
\text { Scruff }\end{array}$ & $\begin{array}{l}97(56) \\
48(49) \\
44(45) \\
4(4) \\
1(2)\end{array}$ \\
\hline $\begin{array}{l}\text { Friend or Couple Referral } \\
\text { Friend } \\
\text { Couple Referral }\end{array}$ & $\begin{array}{l}39(23) \\
24(14) \\
15(9)\end{array}$ \\
\hline Other & $19(11)$ \\
\hline
\end{tabular}

school, participants with associate's degrees or higher were more likely to report multiple partners ( $\mathrm{aOR}=3.04,95 \% \mathrm{CI}$ [1.03-9.02], $\mathrm{p}<0.05$ ). To further assess linear trends, we compared this model with a multivariate model using a linear version of our syndemic scale (i.e., assessing the relative odds of multiple partners as the number of factors increased by one, rather than comparing 0 factors with all other values; not shown in a table). An increase in factors was again associated with an increased odds of multiple partners (aOR $=1.71,95 \% \mathrm{CI}[1.26,2.30], \mathrm{p}<0.01)$. However, likelihood ratio tests confirmed that this approach was not preferable to the original multivariable model $\left(\chi^{2}[3]=1.05, \mathrm{p}>0.05\right)$.

\subsection{Condomless anal intercourse (CAI)}

Bivariate analysis found a significant relationship between number of syndemic factors and CAI $\left(\chi^{2}[4]=14.97, \mathrm{p}<0.05\right)$. In 
Table 2

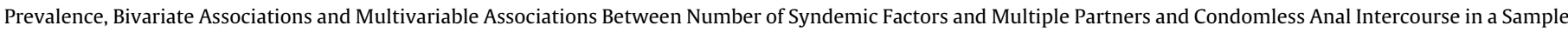
of Latino MSM from New York City $(n=172)$.

\begin{tabular}{|c|c|c|c|c|c|c|c|c|c|c|}
\hline \multirow[t]{2}{*}{ Number of Syndemic Factors ${ }^{\mathrm{a}}$} & \multicolumn{4}{|c|}{$\chi^{2}:$ Multiple Partners (MP) } & \multicolumn{6}{|c|}{ Multivariate Logistic Regression: Multiple Partners (MP) } \\
\hline & No MP: $n(\%)$ & $M P: n(\%)$ & $\chi^{2}(d f)$ & $p$ Value & Adjusted $\mathrm{OR}^{\mathrm{b}}$ & $95 \% C I$ & $p$ Value & Log Likelihood & $L R \chi^{2}(d f)$ & Pseudo $R^{2}$ \\
\hline None $(n=19,10.98 \%)$ & $15(78.95)$ & $4(21.05)$ & $13.74(4)$ & 0.01 & (ref. group) & & & -106.49 & $24.88(12)$ & 0.10 \\
\hline One $(n=39,22.54 \%)$ & $22(56.41)$ & $17(43.59)$ & & & 2.40 & 0.64 to 8.95 & 0.19 & & & \\
\hline Two $(n=53,30.64 \%)$ & $23(43.40)$ & $30(56.60)$ & & & 4.66 & 1.29 to 16.85 & 0.02 & & & \\
\hline Three $(\mathrm{n}=44,25.43 \%)$ & $15(34.09)$ & $29(65.91)$ & & & 7.28 & 1.94 to 27.28 & $<0.01$ & & & \\
\hline Four $(n=18,10.40 \%)$ & $6(33.33)$ & $12(66.67)$ & & & 8.25 & 1.74 to 39.24 & 0.01 & & & \\
\hline
\end{tabular}

Number of Syndemic Factors ${ }^{\mathrm{a}} \quad \chi^{2}$ : Condomless Anal Intercourse (CAI)

No CAI: $n(\%) \quad$ CAIn(\%) $\quad \chi^{2}(d f) \quad p$ Value

None $(n=19,10.98 \%)$

One $(n=39,22.54 \%)$

Two $(n=53,30.64 \%)$

Three $(n=44,25.43 \%)$

Four $(\mathrm{n}=18,10.40 \%)$

$\begin{array}{llll}16(84.21) & 3(15.79) & 14.97(4) & 0.01 \\ 21(53.85) & 18(46.15) & & \\ 27(50.94) & 26(49.06) & & \\ 17(38.64) & 27(61.36) & & \\ 5(27.78) & 13(72.22) & & \end{array}$

Multivariate Logistic Regression: Condomless Anal Intercourse (CAI)

\begin{tabular}{llllll}
\hline Adjusted $O R^{\mathrm{b}}$ & $95 \% \mathrm{CI}$ & $\mathrm{p}$ Value & Log Likelihood & $L R \chi^{2}(\mathrm{df})$ & Pseudo $R^{2}$ \\
(ref. group) & & & -93.28 & $51.88(12)$ & 0.22 \\
3.46 & 0.75 to 15.88 & 0.11 & & & \\
3.69 & 0.84 to 16.21 & 0.08 & & & \\
7.35 & 1.64 to 32.83 & $<0.01$ & & & \\
8.06 & 1.39 to 46.73 & 0.02 & & & \\
\hline
\end{tabular}

a Syndemic factors include reports of clinically significant depression, risky alcohol consumption (i.e. binge or heavy drinking), discrimination, and childhood sexual abuse.

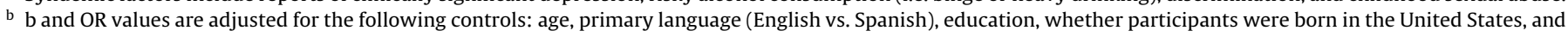
relationship status.

multivariable analyses, participants who reported three or four factors were significantly more likely to report CAI than those who reported none $(\mathrm{aOR}=7.35,95 \% \mathrm{CI}[1.64-32.83], \mathrm{p}<0.05 ; \mathrm{aOR}=8.06$, $95 \%$ CI [1.39-46.73], $\mathrm{p}<0.01$; respectively). The relative odds of $\mathrm{CAI}$ increased as the number of syndemic factors increased. Those who spoke predominantly English were approximately five times as likely to report CAI as those who spoke predominantly Spanish ( $\mathrm{aOR}=4.93,95 \% \mathrm{CI}$ [1.17-20.70], $\mathrm{p}<0.05$ ). Participants in same-sex relationships were four times as likely to report CAI as those were not in such relationships $(\mathrm{aOR}=4.01,95 \% \mathrm{CI}$ [1.77-9.05], $\mathrm{p}<0.01)$. To further assess linear trends, we compared this model with a multivariate model using a linear version of our syndemic scale (not shown in a table). An increase in factors was again associated with an increased odds of $\mathrm{CA}(\mathrm{aOR}=1.59,95 \% \mathrm{CI}[1.15,2.18], \mathrm{p}<0.01)$. However, likelihood ratio tests confirmed that this approach was not preferable to the original multivariable model $\left(\chi^{2}[3]=1.58\right.$, $\mathrm{p}>0.05)$.

\section{Discussion}

This study supports the hypothesis that pervasive psychosocial health conditions exist among Latino MSM, and that the interplay of these conditions magnifies HIV risk. Participants reported high rates of high-risk alcohol consumption, discrimination, childhood sexual abuse, and clinically significant depression. Nearly $90 \%$ of participants reported at least one syndemic factor, and most reported at least two. Moreover, presence of syndemic factors was associated with a greater likelihood of having multiple sexual partners and engaging in CAI.

Providers working with this population should consistently screen for these four conditions. In addition, programs might utilize community strengths and promote coping skills to address multiple syndemic factors including alcohol use, clinically significant depression, and experiences of violence and discrimination (Rhodes et al., 2015; Sun et al., 2015). Herrick and colleagues (2011) pointed out that the vast majority of high-risk MSM are HIV negative, and that community resilience can be an asset in prevention. Studies have proposed that racial/ethnic disparities in HIV rates can be addressed through a strengths-based perspective that emphasizes strong group identity and social supports (Earnshaw et al., 2015).

\subsection{Strengths and limitations}

There are limitations that must be acknowledged. First, our small sample of Latino MSM may not represent Latino MSM or other urban-based MSM, generally. However, we used a purposive stratified sampling strategy to diversify in terms of country of origin, HIV status, HIV/STI testing history, and previous involvement in HIV research (Martinez et al., 2015, 2014). Second, the survey was interviewer-administered and all measures were selfreported; therefore, there may be biases due to imperfect recall, social desirability, embarrassment, etc. However, this approach was suggested by the $C A B$ to promote accessibility to participants with potential literacy problems, including recently-arrived immigrants with limited formal education. Third, we were limited to the sexual behavior variables focused on number of sexual acts, partners, and incidents of CAI; further research should address these behaviors in more detail (e.g., considering CAI within and outside of primary sexual relationships, and incorporating the use of other forms of protection such as PrEP). More efforts are needed to effectively raise awareness of biomedical prevention strategies, and promote community uptake and treatment adherence among Latino MSM and other marginalized populations (Martinez et al., 2016). Fourth, it should be noted that the childhood sexual abuse measure is somewhat conservative. Some participants who experienced exclusively nonconsensual sexual contact in childhood might have answered "no" to our initial question, and thus not have been asked about forcible or coercive experiences. Fifth, our small sample size ensured a lack of statistical power; the considerable confidence intervals further suggest somewhat unstable findings. Finally, this study was cross-sectional and therefore cannot determine causation. Further inquiry is needed to understand the mechanisms whereby syndemic factors influence risk behaviors among Latino MSM.

\subsection{Conclusions and future directions}

To our knowledge, this study is the first to explore the impact of syndemic conditions on adult sexual HIV risk behaviors among predominantly Spanish-speaking Latino MSM. Analyses provide evidence of intertwining factors - clinically significant depression, high-risk alcohol consumption, discrimination, and childhood sexual abuse - that increase HIV risk in this population. To effectively curb HIV, such conditions must be addressed concurrently to reduce risk. Future research should examine 
resilience-based intervention approaches for Latino MSM, such as the development of positive coping skills to address traumatic experiences, reduce harmful alcohol consumption, engage in testtreat to reduce viral load, and promote safer sex practices including condom use.

\section{Conflict of interest}

All authors declare that they have no conflicts of interest.

\section{Contributors}

Omar Martinez conceived of the study and wrote an initial draft of the manuscript. Ethan C. Levine conducted the statistical analyses. Sonya Arreola, Elwin Wu, Miguel Muñoz-Laboy, Scott Edward Rutledge, Carolina Hausmann-Stabile, Larry Icard, Scott D. Rhodes, Alex Carballo-Diéguez, Carlos E. Rodríguez-Díaz, M. Isabel Fernandez, and Theo Sandfort reviewed versions of the manuscript.

\section{Role of funding source}

This research was supported by a center grant from the National Institute of Mental Health to the HIV Center for Clinical and Behavioral Studies at NY State Psychiatric Institute and Columbia University (P30-MH43520; Principal Investigator: Robert H. Remien, Ph.D.). Mr. Omar Martinez was supported by a training grant from the National Institute of Mental Health (T32 MH19139, Behavioral Sciences Research in HIV Infection; Principal Investigator: Theo Sandfort, Ph.D.). The content is solely the responsibility of the authors and does not necessarily represent the official views of the NIMH or the NIH.

\section{Acknowledgments}

The authors thank the potential participants who completed the screening and study participants for their contribution to research. We would like to thank Dr. Patricia Warne, Dr. Madeline Sutton, Mr. Masud Rahman, Ms. Hilda Mitjans, and Mr. Jimmy Liranzo for their research and/or administrative assistance.

\section{References}

Andresen, E.M., Malmgren, J.A., Carter, W.B., Patrick, D.L., 1994. Screening for depression in well older adults: evaluation of a short form of the CES-D (Center for Epidemiologic Studies Depression Scale). Am. J. Prev. Med. 10, 77-84.

Centers for Disease Control and Prevention, 2016. Half of Black Gay Men and a Quarter of Latino Gay Men Projected to be Diagnosed within Their Lifetime. Centers for Disease Control and Prevention, Atlanta, GA, pp. 2016.

Centers for Disease Control, Prevention, 2013. HIV Among Hispanics/Latinos. Centers for Disease Control and Prevention, Atlanta, GA, pp. 2013.

Cheng, S.-T., Chan, A.C.M., 2008. Detecting depression in Chinese adults with mild dementia: findings with two versions of the Center for Epidemiologic Studies Depression Scale (English). Psychiatry Res. 159, 44-49.

Darnall, B.D., Ephraim, P., Wegener, S.T., Dillingham, T., Pezzin, L., Rossbach, P., MacKenzie, E.J., 2005. Depressive symptoms and mental health service utilization among persons with limb loss: results of a national survey. Arch. Phys. Med. Rehabil. 86, 650-658.

Earnshaw, V.A., Bogart, L.M., Dovidio, J.F., Williams, D.R., 2015. Stigma and racial/ethnic HIV disparities: moving toward resilience. Stigma Health 1 $60-74$.

González-Guarda, R.M., Florom-Smith, A.L., Thomas, T., 2011. A syndemic model of substance abuse, intimate partner violence, hiv infection, and mental health among Hispanics. Public Health Nurs. 28, 366-378 (313p).

Halkitis, P., Moeller, R., Siconolfi, D., Storholm, E., Solomon, T., Bub, K., 2013. Measurement model exploring a syndemic in emerging adult gay and bisexual men. AIDS Behav. 17, 662-673.
Kohout, F.J., Berkman, L.F., Evans, D.A., Cornoni-Huntley, J., 1993. Two shorter forms of the CES-D (Center for Epidemiological Studies Depression) depression symptoms index. J. Aging Health 5, 179-193.

Krieger, N., Smith, K., Naishadham, D., Hartman, C., Barbeau, E.M., 2005 Experiences of discrimination: validity and reliability of a self-report measure for population health research on racism and health. Soc. Sci. Med. 61, 1576-1596 (1521).

Martinez, O., Wu, E., Shultz, A.Z., Capote, J., Rios, J.L., Sandfort, T., Manusov, J., Ovejero, H., Carballo-Dieguez, A., Baray, S.C., Moya, E., Matos, J.L., DelaCruz, J.J., Remien, R.H., Rhodes, S.D., 2014. Still a hard-to-reach population? Using social media to recruit Latino gay couples for an HIV intervention adaptation study. J. Med. Internet Res. 16, 1-14.

Martinez, O., Wu, E., Frasca, T., Shultz, A.Z., Fernandez, M.I., López Rios, J., Ovejero, H., Moya, E., Chavez Baray, S., Capote, J., Manusov, J., Anyamele, C.O., López Matos, J., Page, J.S.H., Carballo-Diéguez, A., Sandfort, T.G.M., 2015. Adaptation of a couple-based HIV/STI prevention intervention for Latino men who have sex with men in New York City. Am. J. Men's Health (epub ahead of print).

Martinez, O., Wu, E., Levine, E., Munoz-Laboy, M., Fernandez, I., Bass, S., Moya, E., Frasca, T., Icard, L., Ovejero, H., Carballo-Dieguez, A., Rhodes, S., Chavez-Baray, S., 2016. Integration of social, cultural, and biomedical strategies into an existing couple-based behavioral HIV/STI prevention intervention: voices of Latino male couples. PLoS One 11, e0152361.

Mimiaga, M.J., Biello, K.B., Robertson, A.M., Oldenburg, C.E., Rosenberger, J.G., O'Cleirigh, C., Novak, D.S., Mayer, K.H., Safren, S.A., 2015. High prevalence of multiple syndemic conditions associated with sexual risk behavior and hiv infection among a large sample of spanish- and portuguese-speaking men who have sex with men in latin america. Arch. Sex. Behav. 44, 1869-1878.

Mizuno, Y., Borkowf, C., Millett, G., Bingham, T., Ayala, G., Stueve, A., 2012. Homophobia and racism experienced by Latino men who have sex with men in the United States: correlates of exposure and associations with HIV risk behaviors. AIDS Behav. 16, 724-735 (712p).

O’Brien, M.C., McCoy, T.P., Rhodes, S.D., Wagoner, A., Wolfson, M., 2008. Caffeinated cocktails: energy drink consumption, high-risk drinking, and alcohol-related consequences among college students. Acad. Emerg. Med. 15, 453-460.

O'Leary, A., Jemmott 3rd, J.B., Stevens, R., Rutledge, S.E., Icard, L.D., 2014. Optimism and education buffer the effects of syndemic conditions on HIV status among African American men who have sex with men. AIDS Behav. 18, 2080-2088.

Pignone, M.P., Gaynes, B.N., Rushton, J.L., Burchell, C.M., Orleans, C.T., Mulrow, C.D., Lohr, K.N., 2002. Screening for depression in adults: a summary of the evidence for the U: S. preventive services task force. Ann. Intern. Med. 136, 765-776.

Reece, M., Herbenick, D., Schick, V., Sanders, S.A., Dodge, B., Fortenberry, J.D., 2010. Sexual behaviors, relationships, and perceived health among adult men in the United States: results from a national probability sample. J. Sex. Med. 7, 291-304.

Rhodes, S.D., Bischoff, W.E., Burnell, J.M., Whalley, L.E., Walkup, M.P., Vallejos, Q.M., Quand, S.A., Grzywacz, J.G., Haiying, C., Arcury, T.A., 2010. HIV and sexually transmitted disease risk among male Hispanic/Latino migrant farmworkers in the Southeast: findings from a pilot CBPR Study. Am. J. Ind. Med. 53, 976-983.

Rhodes, S.D., Alonzo, J., Mann, L., Freeman, A., Sun, C.J., Garcia, M., Painter, T.M., 2015. enhancement of a locally developed HIV prevention intervention for Hispanic/Latino MSM: a partnership of community-based organizations, a university, and the Centers for Disease Control and Prevention. AIDS Educ. Prev. 27, 312-332.

Robison, J., Gruman, C., Gaztambide, S., Blank, K., 2002. Screening for depression in middle-aged and older puerto rican primary care patients. J. Gerontol. A. Biol. Sci. Med. Sci. 57, M308-M314.

Substance Abuse and Mental Health Services Administration, 2015. Alcohol. http:// www.samhsa.gov/atod/alcohol accessed on.

Santos, G.-M., Tri, D., Beck, J., Makofane, K., Arreola, S., Pyun, T., Hebert, P., Wilson, P.A., Ayala, G., 2014. Syndemic conditions associated with increased HIV risk in a global sample of men who have sex with men. Sex. Transm. Infect. 90, 250-253.

Singer, M., Clair, S., 2003. Syndemics and public health: reconceptualizing disease in bio-social context. Med. Anthropol. Q. 17, 423-441.

Sun, C.J., García, M., Mann, L., Alonzo, J., Eng, E., Rhodes, S.D., 2015. Latino sexual and gender identity minorities promoting sexual health within their social networks: process evaluation findings from a lay health advisor intervention. Health Promot. Pract. 16, 329-337.

Wendy, Z., O’Brien, N., Forrest, J.I., Salters, K.A., Patterson, T.L., Montaner, J.S.G., Hogg, R.S., Lima, V.D., 2012. Validating a shortened depression scale (10 item CES-D) among HIV-positive people in British Columbia, Canada. PLoS One 7, $1-5$.

Wilson, P.A., Nanin, J., Amesty, S., Wallace, S., Cherenack, E.M., Fullilove, R., 2014. Using syndemic theory to understand vulnerability to HIV infection among Black and Latino men in New York City. J. Urban Health 91, 983-998. 